\title{
Searching for two things at once: Evidence of exclusivity in semantic and autobiographical memory retrieval
}

\author{
ELIZABETH A. MAYLOR, NICK CHATER, and GREGORY V. JONES \\ University of Warwick, Coventry, England
}

\begin{abstract}
We examined whether retrieval from semantic memory (Experiment 1) and autobiographical memory (Experiment 2) is exclusive, or whether people can search for two things at once. In Experiment 1, participants retrieveditems as quickly as possible over $4 \mathrm{~min}$ from single categories (e.g., foods, countries) and from disjunctive categories (e.g., foods or countries). In Experiment 2, participants retrieved autobiographical episodes associated with single cue words (e.g., flower, ticket) or with disjunctive cue words (e.g., flower or ticket). In both experiments, retrieval of items from the disjunctive category did not exceed predictions based on optimal sequencing of retrieval from the corresponding two single categories. That is, exclusivity was observed to occur in retrieval from among multiple nonoverlapping categories in both semantic and autobiographical memory.
\end{abstract}

Does searching for one item in memory exclude the possibility of searching for another item? Or can several memory searches be conducted simultaneously? Historically, this fundamental issue has received little theoretical discussion, but has recently been directly addressed (Pashler, 1998; Rohrer, Pashler, \& Etchegaray, 1998). In this paper, we describe a new way of investigating the dynamics of memory retrieval that allows us to test whether memory search is exclusive both for semantic memory (Experiment 1) and for long-term episodic (autobiographical) memory (Experiment 2).

As discussed recently by Logan and Schulkind (2000), the possibility of parallel memory retrieval is important in several current theories of memory and categorization. In their own empirical work, Logan and Schulkind were able to demonstrate that information can be retrieved about one presented stimulus (such as whether it is a letter or a digit) at the same time that another stimulus is being processed (see also Logan \& Delheimer, 2001). However, this finding of parallelism in the processing of stimulus properties still leaves open the retrieval issue of whether or not the mem-

This research was supported by grants from the Joint Infrastructure Fund (Economic and Social Research Council), The Leverhulme Trust, and by European Commission Grant RTN-HPRN-CT-1999-00065. We are grateful to Emma Bourne, Xan Glowczyk, Lisa Hamilton, and Hannah Williams for collecting the data for Experiment 2 and to Doug Rohrer and Charles Thompson for helpful comments on an earlier version of the article. Experiments $1 \mathrm{~A}$ and $2 \mathrm{~A}$ were presented at the 41 st Annual Meeting of the Psychonomic Society, New Orleans, November 2000. The first author's attendance at the meeting was made possible by a conference grant from The Royal Society of Great Britain. Correspondence concerning this article should be addressed to E. A. Maylor, Department of Psychology, University of Warwick, Coventry CV4 7AL, England (email: elizabeth.maylor@warwick.ac.uk). bership of one category can be searched at the same time as that of a different category.

Rohrer et al. (1998) investigated whether two memories can be retrieved concurrently by first requiring participants to study exemplars from two categories (e.g., beverage: juice, milk, tea, wine; vehicle: bus, car, jeep, truck). After a brief distractor task, participants in their first experiment were required to recall the studied exemplars in one of two ways (dual and mono conditions). If both categories were presented at recall (beverage, vehicle), participants were required to recall all the items in an alternating fashion ( juice, car, milk, bus, tea, etc.), whereas if only one category was presented at recall (beverage), participants were required to recall only half of the items ( juice, milk, tea, wine). The authors argued that if two items from different categories can be retrieved in parallel, retrieval of the next item can begin before the current response is complete. Thus the car-milk interresponse time (IRT) in the dual condition should be shorter than the juice-milk IRT in the mono condition, the bus-tea IRT (dual) should be shorter than the milk-tea IRT (mono), and so on. In contrast, if two items from different categories must be retrieved serially, the above dual IRTs should be either the same as the mono IRTs or greater than the mono IRTs if there is any cost in shifting task sets before each response. The data from both this and a subsequent experiment were consistent with the serial rather than the parallel hypothesis.

In Rohrer et al.'s (1998) experiments, each trial sequence of studying the two categories, performing the distractor task, and recalling the items lasted no longer than 2 min. Thus, although the authors described their study as an investigation of retrieval from "long-term memory" (p. 731), the retention interval was relatively brief. In the present study, we investigated memories with much longer 
periods of retention, focusing on retrieval from semantic memory and from autobiographical memory (cf. Maylor, Chater, \& Brown, 2001).

The present paradigm may be illustrated with the case of retrieval from semantic memory. We asked people to freely generate as many items as possible that belong either to a single category (e.g., foods, countries) or to a disjunctive category (e.g., foods or countries). In the latter case, it would be advantageous for people to conduct two memory searches simultaneously, if they are able to do so. How does the rate of successful retrieval of targets from two categories relate to the rates of retrieval for the relevant single categories? In generation tasks from single categories, it is generally found that the rate at which items are produced decreases monotonically and with negative acceleration and can be modeled as exponential or power function decay (Wixted \& Rohrer, 1994). It is shown here that nonuniformity in the rate of production from single categories can be accommodated within a relatively straightforward analysis of multiple-categories retrieval (see test of exclusivity in the Discussion section of Experiment $1 \mathrm{~A}$ ) while finessing the question of the precise form of the decay function.

We propose that it is useful to distinguish three different theoretical possibilitiesin relating the rate of retrieval from two categories to the rates for the relevant single categories; we term these exclusivity, additivity, and superadditivity. For exclusivity, retrieval occurs from only one or the other category at a time, and, thus, the rate of accumulation of items cannot exceed that for the faster of the single categories. For additivity, retrieval occurs separately from both categories, and, thus, the rate of accumulation of targets cannot exceed that for both single categories combined. For superadditivity, retrieval occurs interactively from the two categories, and, thus, the rate of accumulation of items can exceed the arithmetic sum of the single rates.

An analogous range of possibilities has previously been explored in the case of multiple routes to the recall of a single item (e.g., Jacoby, Toth, Yonelinas, \& Debner, 1994; Jones, 1987). For example, Rubin and Wallace (1989) demonstrated the occurrence of superadditivity in the recalling of red if a person is provided with the cue "name of a color and rhymes with bed," as opposed to either "name of a color" or "rhymes with bed." The occurrence of superadditivity may be regarded as a consequence of inference-making rather than of memory retrieval. To focus on the latter, the categories examined in the present study were selected to have nonoverlapping domains. But for generality, the major theoretical alternatives distinguished here will be identified not as exclusivity and additivity, but as exclusivity and nonexclusivity (where the latter, in principle, includes both additivity and superadditivity). Let us now consider the predictions of exclusive versus nonexclusive memory search models.

If memory search is exclusive, people will only be able to search for items from one category at a time. This means that the rate of retrieval of items from a disjunctive category will be comparable to the rate of retrieval from the in- dividual categories. More strictly, the upper bound on performance would be achieved if people were able to "hop" from searching one category to the other, depending on which search has the higher instantaneous rate of retrieval. So, after one starts by searching Category 1 , for which the retrieval rate is initially higher, the rate of retrieval for Category 1 will decline. When the Category 1 retrieval rate becomes less than the initial retrieval rate for Category 2, the participant should switch to searching for Category 2 items until the rate of retrieving Category 2 items dips below the rate of retrieving Category 1 items, and so on. This upper bound might not be attained, of course, either because people are not able to follow this optimal strategy, or because there are other factors that slow retrieval that have not been taken into account. Specifically, there might be a "switch cost" incurred in switching from one memory search to another. In summary, the exclusive model predicts that the rate of retrieval for a disjunctive category will be comparable to the rates of retrieval for single categories and will not exceed the rate of retrieval obtained by using the optimal strategy sketched above.

If, by contrast, memory search is nonexclusive, we might expect that rates of retrieval for disjunctive categories might substantially exceed rates of retrieval for single categories. Here, the upper bound on performance would be obtained in the purest case of nonexclusivity, where the memory search for items from Category 1 might be conducted in parallel with, and without interference from, search for items from Category 2. In this case, the rate of retrieval for the disjunctive category would be approximately the sum of the rates of retrieval for when each of the component categories was searched alone. Of course, even in this pure case, perfect additivity of rates would not be expected, because of inevitable interference in the production of the items. This would be expected especially in the first few seconds of our tasks, where production is plausibly limited by output speed (particularly in the case of written responses), but would be less of a factor later in the task, where the rate at which items are produced is quite low. Although rate-additivity provides an upper bound on performance, nonexclusive processing does not necessarily predict that performance will be close to additive. There might be a degree of interference between the two searches, or they might draw upon a common resource, for example. Nonetheless, if memory search is nonexclusive, we should expect that disjunctive search rate should exceed the rate of search for individual categories. Strong evidence for nonexclusive search would be obtained if the rate of search for disjunctive categories were to exceed the optimal search rate for exclusive search.

\section{EXPERIMENT 1}

In Experiment 1A, the participants retrieved items from a range of categories in semantic memory under both single and disjunctive conditions. Four of the categories were 
defined on the basis of meaning (e.g., foods, countries), and two were defined on the basis of the lexical form of their members (words beginning with $s$, words beginning with $p$ ). In Experiment 1B, the participants retrieved items from single categories only; this was conducted to test a number of alternative explanations for the apparent exclusivity observed in Experiment 1A. Written responses were required in all conditions of Experiment 1.

\section{Experiment 1A}

\section{Method}

Participants. Thirty undergraduate students aged 18-24 years were randomly assigned to one of three groups $(n=10)$. Group 1 retrieved items from the following categories: words beginning with either $s$ or $p$, musical instruments, foods or countries, and occupations. Group 2 retrieved items from words beginning with $p$, foods, musical instruments or occupations, and countries. Group 3 retrieved items from words beginning with $s$. There were 7, 9, and 7 females in Groups 1, 2, and 3, respectively. All participants were native English speakers.

Apparatus and Stimuli. For each category, there was an identical response sheet divided into eight numbered sections. The names of categories were presented on separate slips of paper. A stopwatch was used to time the experiment.

The categories were selected as follows. The letters $s$ and $p$ are the most frequent and second most frequent initial letters in English, respectively, as estimated by dictionary entries (Brown, 1993). The semantic categories were chosen from 14 "higher level" categories used in a verbal fluency experiment by Herrmann and Murray (1979). The largest estimated category sizes were for (in descending order) countries, foods, occupations, recreation, beverages, plants, and musical instruments. To avoid any semantic overlap between categories (e.g., between foods and beverages), the four categories selected for the present study were countries, foods, occupations, and musical instruments. Foods and countries were paired together, as were musical instruments and occupations, thus providing three pairs of categories of decreasing overall size (i.e., words beginning with $s / p$, foods/countries, musical instruments/occupations).

Procedure. The participants were tested in small groups. They were informed that they would be given a category from which they would be asked to write down as many instances as possible. They were told that when instructed, they should begin writing in the first section of the response sheet but that after $30 \mathrm{sec}$ they would be told to stop and move on to the next section. It was made clear that this meant that they were to finish the word they were writing, move on to the next section, and then continue to write down items from the same category. The participants were told that this procedure would continue until they had completed all eight sections of the response sheet (i.e., after $4 \mathrm{~min}$ ). They were asked to make sure that no item appeared more than once on the response sheet.

The participants in Groups 1 and 2 were additionally instructed that sometimes they would be given two categories, such as colors or buildings, rather than one. Thus each response had to be either a color or a building. They were given examples (red, brown, church, yellow, green, supermarket, etc.) and were told that order of production was not important-what mattered was that they should try to produce as many items as possible.

All participants were told that the first category was words beginning with a particular letter (Groups 2 and 3) or particular letters (Group 1). Before the letter(s) were provided, the participants were instructed that proper names and plurals were not allowed; examples were provided for clarif ication.

When the participants were ready to proceed, they were asked to turn over the slip of paper on which the first category was printed. Once everyone had read the category, the experimenter gave the instruction to begin the task. After completing the first category, the participants in Groups 1 and 2 were then required to repeat the task three more times but with different categories (as listed earlier). There were short rest breaks of 2 min between categories.

\section{Results and Discussion}

One participant in Group 1 did not follow the task instructions correctly for the first category; her data for words beginning with $s$ or $p$ were therefore excluded from the analysis. Repeated and incorrect items were extremely rare. The numbers of acceptable items retrieved in each 30 -sec period were recorded in each condition. It can be seen from the means in Table 1 that the numbers of items retrieved generally declined over time. Note also that the numbers of items retrieved in the either/or conditions were greater than, or quite similar to, the more productive of the two single categories in each period.

Three separate analyses of variance (ANOVAs) were conducted on the total numbers of items retrieved. For words beginning with $s / p$, there was no significant difference between the three conditions $\left[F(2,26)=2.00, M S_{\mathrm{e}}=\right.$ $67.79, p=.16]$. For foods/countries, there was a significant effect of condition $\left[F(2,27)=11.03, M S_{\mathrm{e}}=81.02\right.$, $p<.0005]$. Post hoc comparisons using Bonferroni-Dunn tests (with significant levels of $p$ values appropriately ad-

Table 1

Mean Numbers and Standard Deviations of Items Retrieved in Experiment $1 \mathrm{~A}$ in Each of Eight 30-Second Periods and Totals Retrieved in Four Minutes for Words Beginning With $s / p$, Foods/Countries, and Musical Instruments/Occupations

\begin{tabular}{|c|c|c|c|c|c|c|c|c|c|c|c|c|c|c|c|c|c|c|}
\hline \multirow[b]{3}{*}{ Category } & \multicolumn{16}{|c|}{ Period } & & \\
\hline & \multicolumn{2}{|c|}{1} & \multicolumn{2}{|c|}{2} & \multicolumn{2}{|c|}{3} & \multicolumn{2}{|c|}{4} & \multicolumn{2}{|c|}{5} & \multicolumn{2}{|c|}{6} & \multicolumn{2}{|c|}{7} & \multicolumn{2}{|c|}{8} & \multicolumn{2}{|c|}{ Total } \\
\hline & $M$ & $S D$ & $M$ & $S D$ & $M$ & $S D$ & $M$ & $S D$ & $M$ & $S D$ & $M$ & $S D$ & $M$ & $S D$ & $M$ & $S D$ & $M$ & $S D$ \\
\hline Words beginning with $s$ or $p^{\text {a }}$ & 10.0 & 2.1 & 7.3 & 3.0 & 5.9 & 2.5 & 4.3 & 2.1 & 5.2 & 1.4 & 5.1 & 1.9 & 4.4 & 1.7 & 4.3 & 0.5 & 46.7 & 8.6 \\
\hline Words beginning with $p^{\mathrm{b}}$ & 8.9 & 1.7 & 6.3 & 2.1 & 4.5 & 2.1 & 4.0 & 1.9 & 4.5 & 1.7 & 3.4 & 1.1 & 3.6 & 1.5 & 3.9 & 1.0 & 39.1 & 7.5 \\
\hline Words beginning with $s^{\mathrm{c}}$ & 9.0 & 1.9 & 6.0 & 1.6 & 5.4 & 1.5 & 4.3 & 1.8 & 4.6 & 1.6 & 4.8 & 2.4 & 4.6 & 1.4 & 4.1 & 1.5 & 42.8 & 8.6 \\
\hline Foods or Countries $^{\mathrm{d}}$ & 9.9 & 2.9 & 7.9 & 2.9 & 9.6 & 2.5 & 7.2 & 1.8 & 6.9 & 2.8 & 6.4 & 2.1 & 4.6 & 2.2 & 5.2 & 2.3 & 57.7 & 8.2 \\
\hline Foods $^{\mathrm{b}}$ & 9.1 & 2.7 & 8.2 & 2.4 & 5.9 & 2.2 & 5.8 & 2.5 & 5.1 & 1.9 & 4.6 & 1.7 & 3.9 & 2.6 & 4.0 & 1.5 & 46.6 & \\
\hline Countries $^{b}$ & 10.0 & 1.9 & 7.6 & 2.1 & 6.0 & 1.2 & 5.0 & 1.9 & 3.7 & 2.4 & 2.3 & 1.9 & 2.4 & 1.2 & 1.9 & 2.0 & 38.9 & 9.9 \\
\hline Musical instrum & 9.9 & 1.6 & 6.4 & 1.7 & 5.6 & 1.6 & 5.0 & 0.7 & 4.2 & 1.3 & 4.8 & 1.4 & 4.2 & 1.5 & 4.5 & 2.0 & 44.6 & 6.7 \\
\hline Musical instruments ${ }^{\mathrm{d}}$ & 9.5 & 1.4 & 6.3 & 1.2 & 3.3 & 0.9 & 2.5 & 1.6 & 2.2 & 1.5 & 1.3 & 1.1 & 1.5 & 1.2 & 1.0 & 0.8 & 27.6 & 5 . \\
\hline Occupations $^{\mathrm{d}}$ & 8.2 & 1.2 & 6.0 & 1.9 & 5.1 & 2.0 & 4.9 & 2.1 & 4.4 & 1.7 & 4.4 & 1.4 & 4.2 & 1.5 & 3.7 & 1.8 & 40.9 & 8.4 \\
\hline
\end{tabular}

${ }^{\mathrm{a}}$ Group $1, n=9 . \quad{ }^{\mathrm{b}}$ Group 2, $n=10 . \quad{ }^{\mathrm{c}}$ Group 3, $n=10 . \quad{ }^{\mathrm{d}}$ Group $1, n=10$. 
Table 2

Mean Numbers and Standard Deviations of Items Retrieved in Experiment 1A for Each Category

in the Either/Or Conditions and Switches Between Categories, in Each of Eight 30-Second Periods and Totals for Words Beginning With $s$ or $p$, Foods or Countries, and Musical Instruments or Occupations

\begin{tabular}{|c|c|c|c|c|c|c|c|c|c|c|c|c|c|c|c|c|c|c|}
\hline \multirow[b]{3}{*}{ Category } & \multicolumn{16}{|c|}{ Period } & & \\
\hline & \multicolumn{2}{|c|}{1} & \multicolumn{2}{|c|}{2} & \multicolumn{2}{|c|}{3} & \multicolumn{2}{|c|}{4} & \multicolumn{2}{|c|}{5} & \multicolumn{2}{|c|}{6} & \multicolumn{2}{|c|}{7} & \multicolumn{2}{|c|}{8} & \multicolumn{2}{|c|}{ Total } \\
\hline & $M$ & $S D$ & $M$ & $S D$ & $M$ & $S D$ & $M$ & $S D$ & $M$ & $S D$ & $M$ & $S D$ & $M$ & $S D$ & $M$ & $S D$ & $M$ & $S D$ \\
\hline Words beginning with $s$ & 5.7 & 1.2 & 3.1 & 2.7 & 2.4 & 1.9 & 2.9 & 2.0 & 2.1 & 1.6 & 3.4 & 1.5 & 2.0 & 1.2 & 2.1 & 0.8 & 23.8 & 6.3 \\
\hline Switches & 2.7 & 2.1 & 1.9 & 1.2 & 1.7 & 1.3 & 1.7 & 0.9 & 2.2 & 1.0 & 2.0 & 1.4 & 1.6 & 0.9 & 1.6 & 0.7 & 15.2 & 5.5 \\
\hline Foods & 5.5 & 3.9 & 3.5 & 4.2 & 1.5 & 2.2 & 2.0 & 3.3 & 3.8 & 4.6 & 2.8 & 3.4 & 1.9 & 1.9 & 4.0 & 2.7 & 25.0 & 12.7 \\
\hline Musical instruments & 7.1 & 4.5 & 3.8 & 3.6 & 1.5 & 1.7 & 0.0 & 0.0 & 1.2 & 1.9 & 1.5 & 2.5 & 1.4 & 1.7 & 0.9 & 1.3 & 17.4 & 7.1 \\
\hline Occupations & 2.8 & 3.2 & 2.6 & 2.5 & 4.1 & 2.4 & 5.0 & 0.7 & 3.0 & 1.9 & 3.3 & 2.1 & 2.8 & 2.4 & 3.6 & 2.5 & 27.2 & 6.3 \\
\hline Switches & 0.5 & 0.7 & 0.5 & 0.7 & 0.8 & 0.6 & 0.2 & 0.4 & 0.6 & 0.7 & 0.7 & 0.7 & 0.6 & 0.7 & 0.9 & 0.9 & 4.8 & 3.4 \\
\hline
\end{tabular}

justed for multiple comparisons) revealed significant differences between foods or countries and foods, between foods or countries and countries, but not between foods and countries. For musical instruments/occupations, there was also a significant effect of condition $[F(2,27)=$ $\left.16.55, M S_{\mathrm{e}}=48.29, p<.0001\right]$. Post hoc comparisons revealed significant differences between musical instruments or occupations and musical instruments, between musical instruments and occupations, but not between musical instruments or occupations and occupations. Thus, in only one of the three tasks did the either/or condition's total number of items retrieved significantly exceed that for both the single condition totals - namely, foods/countries.

A breakdown of performance in the either/or conditions is provided in Table 2. The table shows the numbers of items retrieved from each of the two categories, together with the numbers of times the participants switched between them in each 30 -sec period. The total numbers of items retrieved in the either/or conditions expressed as proportions of the totals retrieved in the single category conditions (see Table 1 ) were .59 ( $p$ words), .56 ( $s$ words), .54 (foods), .84 (countries), .63 (musical instruments), and .67 (occupations). An ANOVA was conducted on the numbers of switches, with task (3 levels: $s$ or $p$ words, foods or countries, and musical instruments or occupations) as the between-subjects variable and period ( 8 levels) as the within-subjects variable. There was a significant effect of $\operatorname{task}\left[F(2,26)=20.58, M S_{\mathrm{e}}=1.99, p<.0001\right]$, but no effect of period $\left[F(7,182)=1.23, M S_{\mathrm{e}}=0.67\right]$ and no interaction $\left[F(14,182)=1.21, M S_{\mathrm{e}}=0.67\right]$. It can be seen from Table 2 that the participants switched between $s$ and $p$ words approximately three times more often than they did between categories in the other two tasks. The absence of an effect of period, combined with the marked decline in retrieval over time (Table 1), indicates that the numbers of consecutive items retrieved from the same category decreased with time on the task.

Figure 1 shows cumulative retrieval plotted as a function of time for the either/or and single-category conditions (derived from Table 1). Note first that all functions were negatively accelerated, consistent with random sampling with replacement from a finite search set (see Wixted \& Rohrer, 1994). Second, the rates of approach to asymptote tended to be slower for the letter categories than for the semantic categories (with the possible exception of occupations), consistent with evidence that the rate of approach to asymptote is inversely related to category size (again, see Wixted \& Rohrer, 1994, for a summary).

Test of exclusivity. If search of the two categories in the either/or conditions (A/B) is exclusive (i.e., search occurs for just one category at a time), an initial prediction might be that cumulative retrieval $(R)$ should equal the greater of the cumulative retrievals for $\mathrm{A}$ and for $\mathrm{B}$ :

$$
R(\mathrm{~A} / \mathrm{B})=\operatorname{Max}[R(\mathrm{~A}), R(\mathrm{~B})] .
$$

In fact, as can be seen in Figure 1, cumulative retrieval for $\mathrm{A} / \mathrm{B}$ was slightly greater than $\operatorname{Max}(\mathrm{A}, \mathrm{B})$ in all cases, with the difference reaching significance for foods/countries (Figure 1B). However, this advantage for A/B could be attributable to variation in the ease of production across items within a category. That is, any advantage in $\mathrm{A} / \mathrm{B}$ relative to $\operatorname{Max}(A, B)$ could be the result of the participants in the $\mathrm{A} / \mathrm{B}$ condition being able to generate "easy" examples from both A and B, instead of "easy" and then "difficult" items from just the one category that contributes to $\operatorname{Max}(A, B)$.

An obvious solution is to modify the exclusivity prediction so that "easy" items from both A and B are embraced. If the total response time is $T$ periods (where $T=8$ ), then

$$
\begin{aligned}
R(\mathrm{~A} / \mathrm{B})= & \operatorname{Max}\{[R(\mathrm{~A}) \text { over the first } t \text { periods }] \\
& +[R(\mathrm{~B}) \text { over the first }(T-t) \text { periods }]\}
\end{aligned}
$$

Alternatively, an argument could be made for calculating the maximum total produced by combining items retrieved from any $t$ periods of A with any $(T-t)$ periods of B. In this case, the time periods selected from A and B need not necessarily be adjacent or, indeed, include the first period. We prefer Equation 2 because the critical comparison is with the total number of items retrieved in the first $T$ adjacent periods of the disjunctive condition. In practice, because the numbers of items retrieved in each 

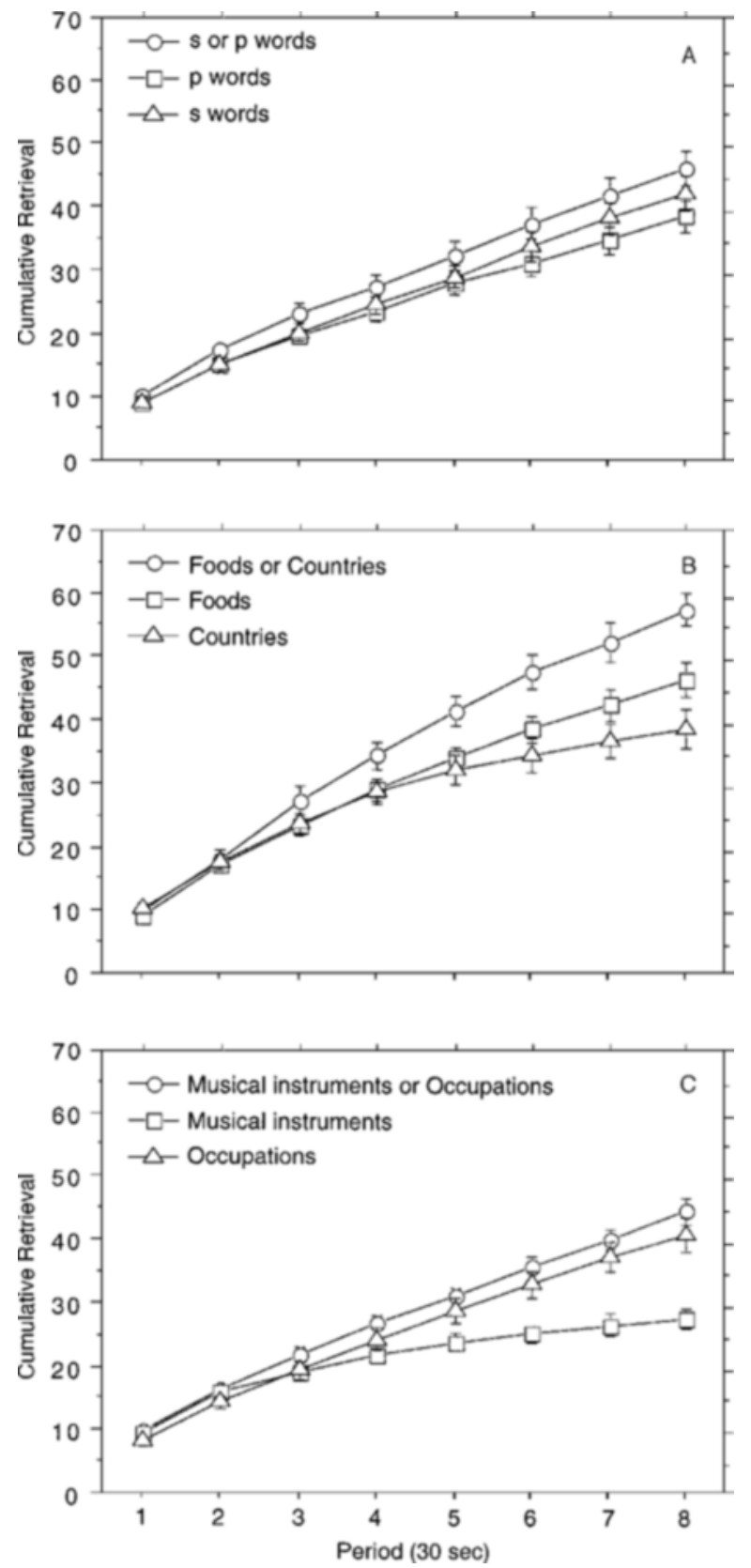

Figure 1. Cumulative numbers of items retrieved over $4 \mathrm{~min}$ in Experiment 1A for (A) words beginning with $s$ or $p$ (Group 1, $n=$ 9), words beginning with $p$ (Group $2, n=10$ ), and words beginning with $s(\mathrm{Group} \mathrm{3,n=10)}$; (B) foods or countries (Group 1, $n=10$ ), foods, and countries (Group 2, $n=10$ ); and $(C)$ musical instruments or occupations (Group $2, n=10$ ), musical instruments, and occupations (Group 1, $n=10$ ). Error bars represent $\pm 1 S E$.

period generally decrease monotonically over time, Equation 2 usually produces identical values to those from this alternative approach.

For words beginning with $s / p$, Equation 2 was applied to the mean cumulative frequencies (Figure 1A) for words beginning with $p$ (Group 2) and for words beginning with $s$ (Group 3). Equation 2 was maximal when the first two periods of words beginning with $p$ were combined with the first six periods of words beginning with $s .{ }^{1}$ This yielded a single predicted total (see Table 3 ) that was compared with the observed totals for words beginning with $s$ or $p$ (Group 1) by using a one-sample $t$ test. The predicted total of 49.3 was not significantly higher than the observed mean of $46.7[t(8)=0.92, p=.38]$.

In contrast to words beginning with $s / p$ (where three different groups of participants retrieved words beginning with $s$ or $p, p$, and $s$ ), for foods/countries and musical instruments/occupations, each participant retrieved items from two single categories and one disjunctive category. Equation 2 could therefore be applied to each individual participant (foods and countries for Group 2, musical instruments and occupations for Group 1), yielding the mean predicted totals shown in Table $3 .^{2}$ To compare these with the observed totals for foods or countries (Group 1) and musical instruments or occupations (Group 2), which are also shown in Table 3, a twoway ANOVA was conducted with group (1 and 2 ) as the between-subjects variable and condition (observed vs. predicted) as the within-subjects variable. The two groups did not differ significantly overall $(F<1)$. The observed mean (51.2) was significantly lower than the predicted mean $(54.3)\left[F(1,18)=4.58, M S_{\mathrm{e}}=21.67, p<\right.$ $.05]$. Finally, the two-way interaction was highly significant $\left[F(1,18)=64.80, M S_{\mathrm{e}}=21.67, p<.0001\right]$, indicating that the participants retrieved more foods and countries $(M=58.7)$ than musical instruments and occupations $(M=46.8)$.

In summary, the total numbers of items retrieved in the either/or conditions were always lower than the totals predicted on the assumption of exclusivity (i.e., only one category can be searched at a time). For categories defined by meaning (foods, countries, musical instruments, and occupations), the observed totals were significantly

Table 3

Mean Totals and Standard Deviations of Items Retrieved in Four Minutes and Two Minutes in the Either/Or Conditions of Experiment 1A (Observed) and Mean Totals Predicted on the Basis of Exclusivity

\begin{tabular}{|c|c|c|c|c|}
\hline \multirow[b]{2}{*}{ Category } & \multicolumn{2}{|c|}{ Observed } & \multicolumn{2}{|c|}{ Predicted } \\
\hline & $M$ & $S D$ & $M$ & $S D$ \\
\hline \multicolumn{5}{|c|}{ Four Minutes } \\
\hline Words beginning with $s$ or $p$ & $46.7^{\mathrm{a}}$ & 8.6 & $49.3^{b}$ & - \\
\hline Foods or countries & $57.7^{\mathrm{c}}$ & 8.2 & $59.6^{d}$ & 7.8 \\
\hline $\begin{array}{l}\text { Musical instruments } \\
\text { or occupations }\end{array}$ & $44.6^{\mathrm{d}}$ & 6.7 & $49.0^{c}$ & 8.7 \\
\hline \multicolumn{5}{|c|}{ Two Minutes } \\
\hline Words beginning with $s$ or $p$ & $27.6^{\mathrm{a}}$ & 6.6 & $30.2^{b}$ & - \\
\hline $\begin{array}{l}\text { Foods or countries } \\
\text { Musical instruments }\end{array}$ & $34.6^{\mathrm{c}}$ & 6.8 & $35.6^{\mathrm{d}}$ & 5.8 \\
\hline or occupations & $26.9^{d}$ & 2.9 & $30.4^{\mathrm{c}}$ & 5.0 \\
\hline
\end{tabular}

${ }^{\mathrm{a}}$ Group $1, n=9 . \quad{ }^{\mathrm{b}}$ Group 2, $n=10 . \quad{ }^{\mathrm{c}}$ Group $3, n=10 . \quad{ }^{\mathrm{d}}$ Group $1, n=$ 10. 
lower than the predicted totals. For categories defined by form (words beginning with $s$ and $p$ ), the observedpredicted difference (in this case, a between-subjects comparison) was similar in magnitude but did not reach significance.

One possible explanation for the failure to find greater retrieval in the either/or conditions than predicted on the basis of exclusivity can be addressed in a preliminary way by further data analysis of Experiment $1 \mathrm{~A}$. This concerns the possibility of fatigue - note that the last of the preceding analyses compared performance over a longer time period (4 min) in the either/or categories than in the single categories (up to $3 \mathrm{~min}$ ). Although it seems unlikely that the participants would tire appreciably between 3 and $4 \mathrm{~min}$, we examined this possible explanation by considering the first four periods rather than all eight periods of the task ( $T=4$ in Equation 2). The observed and predicted totals are shown in Table 3. For words beginning with $s / p$, the maximal predicted total (Equation 2) was formed by combining the first two periods of words beginning with $p$ and the first two periods of words beginning with $s$ from Figure 1A. With a one-sample $t$ test, the predicted total of 30.2 was not significantly higher than the observed mean of $27.6[t(8)=1.21, p=.26]$. The data for foods/countries and musical instruments/occupations were analyzed as before (see Table 3 for means). Again, there was no overall difference between Groups 1 and $2(F<1)$. The difference between the observed mean (30.8) and the predicted mean (33.0) approached significance $\left[F(1,18)=3.17, M S_{\mathrm{e}}=15.99, p<.10\right]$. More foods and countries were retrieved $(M=35.1)$ than were musical instruments and occupations $(M=28.7)$, as indicated by a significant two-way interaction $\left[F(1,18)=26.02, M S_{\mathrm{e}}=\right.$ $15.99, p<.0001]$. Thus, the main pattern of findings was unaltered by restricting data analysis to retrieval based on 2 min rather than $4 \mathrm{~min}$, contrary to the suggestion that fatigue might have unduly limited the observed totals for the disjunctive categories.

To conclude, the results of Experiment 1A demonstrate that two different categories in semantic memory cannot be searched in parallel; in other words, search is exclusive. The conclusion was the same whether the participants switched frequently (words beginning with $s / p$ ) or infrequently (foods/ countries, musical instruments/occupations), and whether the categories were defined in terms of meaning (foods/ countries, musical instruments/occupations) or form (words beginning with $s / p$ ). Retrieval of items from the disjunctive categories, was actually worse than predicted on the basis of optimal sequencing of retrieval from the corresponding two single categories (see Rohrer et al., 1998, for a similar finding), which can be attributed to the cost of switching task set from one category to the other on several occasions during the 4 min (e.g., Rogers \& Monsell, 1995).

\section{Experiment 1B}

Although the additional analyses of Experiment 1A would appear to argue against fatigue as an explanation for the failure to find evidence of nonexclusive search, it remains the case that the comparisons shown in Table 3 are based on retrieval from longer continuous periods of time for observed than for predicted totals. Moreover, in addition to physical fatigue, there may also be mental fatigue in the form of proactive or output interference from items already produced; this would have a greater adverse effect on the observed totals (based on output over $4 \mathrm{~min}$ in the disjunctive condition) than on the predicted totals (based on output over less than 4 min in each of two single conditions). An obvious comparison condition to investigate such possibilities would be a "successive" condition in which participants retrieve items for $4 \mathrm{~min}$, first from one single category and then from another single category, without any rest break between the two categories. Thus, in Experiment 1B, the participants retrieved words beginning with $s(2 \mathrm{~min})$ then words beginning with $p$ ( $2 \mathrm{~min}$ ), foods ( $2 \mathrm{~min}$ ) then countries ( $2 \mathrm{~min}$ ), and musical instruments $(2 \mathrm{~min})$ then occupations $(2 \mathrm{~min})$. Note that equal periods of 2 min for each of the two single categories came close to optimal in the tests of exclusivity in Experiment $1 \mathrm{~A}$ for words beginning with $s / p$ and for foods/countries, but not for musical instruments/occupations (see notes 1 and 2). If the totals in the successive condition of Experiment $1 \mathrm{~B}$ are similar to those in the disjunctive condition of Experiment 1A (at least for words beginning with $s / p$ and foods/countries), this would support our conclusion that search is exclusive. However, poorer recall in the successive condition than in the disjunctive condition would provide evidence of nonexclusive search.

Another possible factor contributing to the apparent exclusivity observed in Experiment $1 \mathrm{~A}$ is that of writing speed. Thus, it could be argued that output in the disjunctive condition was, at least initially, limited by the maximum rate at which items could be written down. However, we do not regard this potential constraint as problematic for the following reasons: First, it can be seen from Table 1 that the participants retrieved fewer items in the second 30sec period than in the first 30 -sec period, suggesting that any potential writing bottleneck would have occurred in the initial period only. Second, if the participants were unable to write down immediately all the items they had retrieved, the remaining items could still be reported eventually, if they could be stored until a later period. Importantly, any such delays would have no effect on our test of exclusivity (Equation 2). Nevertheless, we included a measure of writing speed in Experiment 1B in order to assess its possible impact on the results of Experiment 1A.

\section{Method}

Participants. Thirteen undergraduate students (10 females, 3 males) aged 18-20 years participated in the experiment. They were all native English speakers.

Apparatus and Stimuli. For each pair of categories, there were two response sheets; the first was divided into eight sections numbered 1-4 twice, and the second was blank. The names of categories were read out by the experimenter at the same time that they were 
being presented on a large screen via an overhead projector. The categories were those of the six single conditions of Experiment 1A.

Procedure. The participants were tested in a single group. As in Experiment 1A, they were informed that they would be given a category and that their task was to write down as many instances of that category as possible. They were to begin writing in the top section of the response sheet (numbered 1), but after $30 \mathrm{sec}$ they were to stop (after finishing the word they were writing) and move on to the next section (numbered 2). The participants were told that this procedure would continue until they had completed the first four sections numbered $1-4$ of the response sheet (i.e., after $2 \mathrm{~min}$ ). Without any break, they were then immediately to be given a second category from which they were to write down instances in the next four sections of the response sheet ( $30 \mathrm{sec}$ per section) under the same procedure. As before, the participants were instructed to make sure that they did not write down the same item twice on the response sheet.

After a short rest break of $2 \mathrm{~min}$, the participants were asked to copy onto the blank sheet of paper as many of their responses as possible in $30 \mathrm{sec}$ as a test of their writing speed. They were instructed to start by copying down the items from Section 1 of the first category, then from Section 1 of the second category, and then from Section 2 of the first category, and so on, until they were told to stop.

The procedures above were carried out with the following categories: (1) words beginning with $s$ immediately followed by words beginning with $p$, (2) foods then countries, and (3) musical instruments then occupations. There were short rest breaks of 2 min between pairs of categories. Prior to the first pair of categories, the participants were additionally instructed to exclude proper names and plurals.

\section{Results and Discussion}

Repeated and incorrect items were extremely rare. The mean total numbers of acceptable responses produced in 4 min for each pair of categories are shown in Table 4. It can be seen that, for words beginning with $s$ then $p$ and for foods then countries, the totals were almost identical to the observed totals in Table 3, whereas the total was somewhat lower for musical instruments then occupations. Statistical comparisons between these totals revealed no significant differences between the successive (Experiment 1B) and disjunctive (Experiment 1A) conditions $[t(20)=0.04$ for words beginning with $s / p ; t(21)=0.07$ for foods/countries; $t(21)=1.55$ for musical instruments/occupations; all $p \mathrm{~s}>$ .1]. Although not significant, the slightly lower total for musical instruments then occupations is consistent with the point made earlier that an equal division of the $4 \mathrm{~min}$ between categories was less than optimal for this particular combination (see note 2 ) ${ }^{3}$ It is clear from these results that fatigue can be discounted as an explanation for the failure to find evidence of nonexclusive search in Experi-

Table 4

Mean Numbers and Standard Deviations of Items Retrieved in Experiment 1B (Successive Condition; Two Minutes Per Category) in Four Minutes (Total), in the First 30 Seconds (Period 1), and the Numbers Copied in 30 Seconds (Maximum)

\begin{tabular}{|c|c|c|c|c|c|c|}
\hline \multirow[b]{2}{*}{ Categories } & \multicolumn{2}{|c|}{ Total } & \multicolumn{2}{|c|}{ Period 1} & \multicolumn{2}{|c|}{ Maximum } \\
\hline & $M$ & $S D$ & $M$ & $S D$ & $M$ & $S D$ \\
\hline $\begin{array}{l}\text { Words beginning with } s \text { then } \\
\text { words beginning with } p\end{array}$ & 46.5 & 7.8 & 9.2 & 2.2 & 16.2 & 2.3 \\
\hline Foods then countries & 57.5 & 7.6 & 10.7 & 1.4 & 14.1 & 1.5 \\
\hline $\begin{array}{l}\text { Musical instruments } \\
\text { then occupations }\end{array}$ & 40.3 & 6.5 & 9.3 & 1.7 & 13.7 & 1.8 \\
\hline
\end{tabular}

ment $1 \mathrm{~A}$. Thus, having controlled for the length of time over which the participants continuously retrieved items (i.e., $4 \mathrm{~min}$ ), there was no significant advantage in searching two categories at once (disjunctive condition, Experiment 1A), as compared with searching one category followed by another (successive condition, Experiment 1B).

The mean numbers of items retrieved in the first 30-sec period of each of the 4-min tasks (words beginning with $s$, foods, musical instruments) are also shown in Table 4. It can be seen that these were between three and seven items fewer than the numbers of items participants were able to copy down from their response sheets in $30 \mathrm{sec}$ (see final column of Table 4). Paired $t$ tests confirmed that the participants were indeed physically capable of writing down significantly more items than they did in the retrieval task $[t(12)=8.97,7.58$, and 10.52 for words beginning with $s / p$, foods/countries, and musical instruments/occupations, respectively; all $p \mathrm{~s}<.0001]$. It should be recognized that even the numbers in the final column of Table 4 are probably underestimates of the participants' maximum writing speeds because of time lost in their scanning between the two response sheets during the copying task. We therefore conclude that writing speed was probably not a significant factor in limiting retrieval in the disjunctive condition of Experiment 1A, even in the initial 30-sec period. In summary, the results of Experiment $1 \mathrm{~B}$ allow us to discount two possible factors (fatigue and writing speed) that could be argued to have contributed to the failure to find evidence of nonexclusive search in Experiment 1A.

\section{EXPERIMENT 2}

We further examined the generality of the exclusivity of memory retrieval in our second experiment by examining retrieval from long-term episodic memory. For this, we adapted the Galton-Crovitz-Rubin cue-word technique (Crovitz \& Schiffman, 1974; Galton, 1879; Rubin, 1982) commonly used in the study of autobiographical memory (see Conway, 1990, for a summary). Participants are presented with cue words of high word frequency and imageability and are asked to retrieve a specific autobiographical memory associated with each cue word. As in Experiment 1A, the participants in Experiment 2A were required to write down as many autobiographical memories as possible in response to single cue words (e.g., flower, ticket) and to disjunctive cue words (e.g., flower or ticket). In Experiment 2B, vocal rather than written responses were required. Again, we applied the test of exclusivity to the data in order to determine whether retrieval from two different categories in autobiographical memory (in this case, flower episodes and ticket episodes) was exclusive or not.

\section{Experiment 2A}

\section{Method}

Participants. Twenty undergraduate students (19 females, 1 male) aged 20-21 years were randomly assigned to one of two groups $(n=$ 10). Group 1 retrieved memories associated with the following cue 
words: flower, fire or picture, and ticket. Group 2 retrieved memories associated with the words fire, flower or ticket, and picture. All participants were native English speakers.

Apparatus and Stimuli. The apparatus was the same as that for Experiment 1A. The stimuli were selected on the basis of a pilot study in which participants (who did not take part in the main experiment) were given 18 cue words taken from a study of autobiographical memory by Rubin, Wetzler, and Nebes (1986). The participants were asked to produce as many specific personal memories as possible associated with each cue word in a limited time. The four cue words producing the most memories were chosen for the present experiment-namely, fire, flower, picture, and ticket. To avoid alliteration, fire was paired with picture, and flower was paired with ticket.

Procedure. The procedure was the same as that for Experiment $1 \mathrm{~A}$, except that the participants were instructed that they would be presented with a word and that their task was to write down as many of their own specif ic personal memories associated with that word as possible. It was emphasized that the event did not have to be important or even interesting and that it could come from any point in their lives, even as recently as that morning. However, the event did have to be specific - the example of recalling a trip to see a particular film in response to the word cinema was provided in order to make this clear. The participants were asked to summarize each memory in no more than two words. It was noted that the experimenter did not need to understand the memory description.

As in Experiment 1A, the participants were additionally instructed that sometimes they would be given two words, such as flag or sugar, rather than one. Thus, each response had to be a memory associated with either a flag or sugar. Examples were provided of recalling waving a flag at a street carnival in 1996 and of giving up sugar in tea at the age of 10, which perhaps could be recorded as "street carnival" and "tea-10." As before, it was emphasized that responses to the two words could be recalled in any order. ${ }^{4}$

The participants in both groups performed the task three times with different cue words as listed earlier.

\section{Results and Discussion}

All participants followed the task instructions correctly, and there were no repeated items. The numbers of memories retrieved in each 30 -sec period are shown in Table 5 for each condition. It can be seen that the participants generally retrieved more memories in the early periods than in the later periods. For firelpicture, the numbers of memories retrieved in the either/or condition were slightly lower than, or similar to, each of the two single cue word conditions, whereas for flower/ticket, the numbers of memories re- trieved in the either/or condition were higher than in each of the two single cue word conditions in each period.

The total numbers of memories retrieved were submitted to two separate ANOVAs. For fire/picture, there was no significant difference between the three conditions $(F<$ 1). For flower/ticket, there was a significant effect of condition $\left[F(2,27)=6.72, M S_{\mathrm{e}}=25.03, p<.005\right]$, with post hoc comparisons revealing significant differences between flower or ticket and flower, and between flower or ticket and ticket, but not between flower and ticket.

The participants varied somewhat in their ability to recall memories, and it is apparent from Table 5 that the participants randomly assigned to Group 1 were rather less productive overall than the participants randomly assigned to Group 2. It is therefore important to consider the average results across the two pairs of words, which show that the total number of memories retrieved in the either/or condition $(M=14.3)$ was slightly greater than the more productive of the two single categories $(M=12.1)$, as in Experiment $1 \mathrm{~A}$.

Cumulative retrieval over the eight 30 -sec periods is shown in Figure 2 for the either/or and single word conditions (derived from Table 5). These functions generally resembled those of Figure 1 in their being negatively accelerated (cf. Wixted \& Rohrer, 1994).

Test of exclusivity. Equation 2 was applied to the present data in the same way as for the foods/countries and musical instruments/occupations conditions of Experiment $1 \mathrm{~A}$. The resulting predicted means are shown in Table 6 together with the observed totals for the either/or conditions. The data were submitted to a two-way ANOVA with group (1 and 2) as the between-subjects variable and condition (observed vs. predicted) as the within-subjects variable. There was a significant effect of group $[F(1,18)=$ $\left.4.73, M S_{\mathrm{e}}=51.86, p<.05\right]$, indicating that the participants assigned to Group $1(M=13.3)$ were generally worse at retrieving autobiographical memories than were the participants assigned to Group $2(M=18.3)$. The observed mean (14.3) was significantly lower than the predicted mean $(17.3)\left[F(1,18)=14.50, M S_{\mathrm{e}}=6.41, p<.005\right]$. Finally, the two-way interaction was marginally significant $[F(1,18)=$ $\left.3.75, M S_{\mathrm{e}}=6.41, p<.07\right]$, indicating a tendency for the

Table 5

Mean Numbers and Standard Deviations of Items Retrieved in Experiment $2 \mathrm{~A}$ in Each of Eight 30-Second Periods and Totals Retrieved in Four Minutes for Memories Associated with Fire/Picture, and Memories Associated with Flower/Ticket

\begin{tabular}{|c|c|c|c|c|c|c|c|c|c|c|c|c|c|c|c|c|c|c|}
\hline \multirow[b]{3}{*}{ Category } & \multicolumn{16}{|c|}{ Period } & & \\
\hline & \multicolumn{2}{|c|}{1} & \multicolumn{2}{|c|}{2} & \multicolumn{2}{|c|}{3} & \multicolumn{2}{|c|}{4} & \multicolumn{2}{|c|}{5} & \multicolumn{2}{|c|}{6} & \multicolumn{2}{|c|}{7} & \multicolumn{2}{|c|}{8} & \multicolumn{2}{|c|}{ Total } \\
\hline & $M$ & $S D$ & $M$ & $S D$ & $M$ & $S D$ & $M$ & $S D$ & $M$ & $S D$ & $M$ & $S D$ & $M$ & $S D$ & $M$ & $S D$ & $M$ & $S D$ \\
\hline $\begin{array}{l}\text { Memories associated } \\
\text { with fire } \text { or picture }\end{array}$ & 2.7 & 0.9 & 1.9 & 1.0 & 1.5 & 1.1 & 1.3 & 1.2 & 1.4 & 0.5 & 0.7 & 0.7 & 0.9 & 1.2 & 0.6 & 0.8 & 11.0 & 5.0 \\
\hline Memories associated with fire & 4.0 & 1.4 & 2.4 & 0.7 & 1.1 & 0.9 & 1.5 & 0.9 & 0.9 & 0.6 & 1.3 & 0.9 & 0.8 & 0.8 & 0.4 & 0.7 & 12.4 & 2.3 \\
\hline Memories associated with picture ${ }^{\mathrm{b}}$ & 3.1 & 1.4 & 2.3 & 0.8 & 1.9 & 1.0 & 1.7 & 0.7 & 1.2 & 0.9 & 1.2 & 0.9 & 1.1 & 1.4 & 0.5 & 0.7 & 13.0 & 5.0 \\
\hline 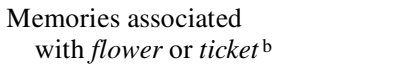 & 4.2 & 1.8 & 3.7 & 1.2 & 2.1 & 1.2 & 1.7 & 0.7 & 2.0 & 1.1 & 1.7 & 0.8 & 1.3 & 1.1 & 0.8 & 0.8 & 17.5 & 6.0 \\
\hline Memories associated with ticket $^{\mathrm{a}}$ & 2.9 & 0.7 & 1.7 & 0.7 & 1.4 & 1.0 & 1.1 & 0.7 & 1.0 & 0.9 & 0.6 & 0.7 & 0.5 & 0.5 & 0.6 & 0.7 & 9.8 & 3.9 \\
\hline
\end{tabular}

aGroup 1. bGroup 2. 

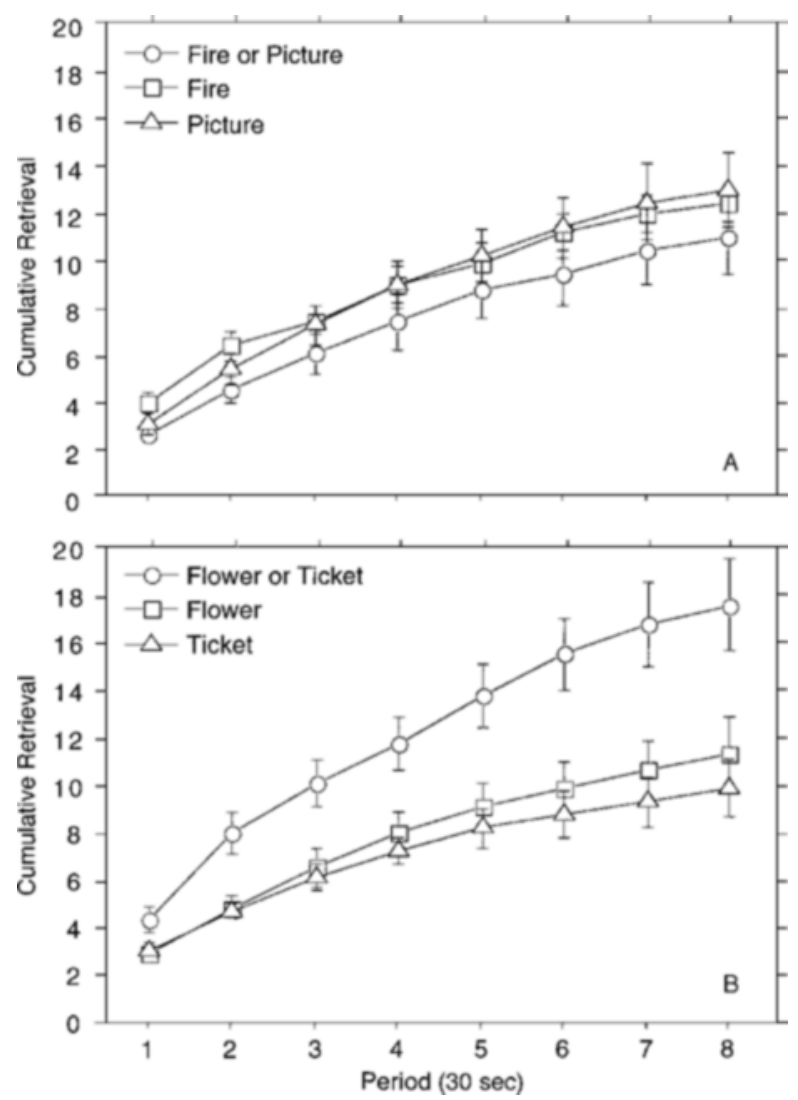

Figure 2. Cumulative numbers of items retrieved over $4 \mathrm{~min}$ in Experiment 2A for (A) memories associated with fire or picture (Group 1, $n=10)$, fire, and picture (Group 2, $n=10$ ), and (B) memories associated with flower or ticket (Group 2, $n=10$ ), flower, and ticket (Group 1, $n=10$ ). Error bars represent $\pm 1 S E$.

participants to produce fewer fire and picture memories $(M=15.0)$ than flower and ticket memories $(M=16.6)$.

To summarize, the participants failed to retrieve more autobiographical memories from disjunctive categories than predicted on the basis of optimal sequencing of retrieval from single categories. Indeed, performance in the disjunctive categories was again significantly worse than predicted, probably reflecting the time costs associated with switching between categories.

\section{Experiment 2B}

Although significantly fewer memories were retrieved overall in the disjunctive conditions of Experiment 2A than predicted, the observed total was actually lower than the predicted total for only one of the two pairs of cue words (see Table 6). This asymmetry was attributed to an overall difference in performance between the participants randomly assigned to the two experimental groups. Nevertheless, it remains important to demonstrate that exclusive search in autobiographical memory applies to more than one pair of cue words. One aim of Experiment 2B was therefore to replicate Experiment $2 \mathrm{~A}$, with the expectation that random assignment of participants to groups would not again result in mismatched groups. An additional aim of Experiment 2B was to extend the procedure to vocal responses as a further test of the influence of limitations in writing speed on the results of Experiments 1A and 2A.

\section{Method}

Participants. Twenty undergraduate students aged 18-25 years were randomly assigned to one of two groups ( 5 females, 5 males per group), with each group being further divided in half by counterbalancing as follows: Group 1a retrieved memories associated with the cue words flower, fire or picture, and ticket. Order was reversed for Group $1 \mathrm{~b}$ (i.e., ticket, picture or fire, and flower). Group 2a retrieved memories associated with the cue words fire, flower or ticket, and picture. Order was reversed for Group $2 \mathrm{~b}$ (i.e., picture, ticket or flower, and fire). All participants were native English speakers.

Apparatus and Stimuli. The names of categories were again presented on slips of paper. The participants' vocal responses were tape-recorded for later analysis.

Procedure. The procedure was the same as that for Experiment $2 \mathrm{~A}$, with the following exceptions. First, the participants were tested individually rather than in groups. Second, the participants were required to vocalize their responses rather than write them down. Third, they were allowed only $3 \mathrm{~min}$ for each category (or pair of categories), with a 1-min rest break between categories.

\section{Results and Discussion}

The numbers of memories retrieved in each of the six 30 -sec periods for each condition were recorded. Here, for the sake of brevity, we proceed immediately to the test of exclusivity, whereby Equation 2 was applied to the data in the same way as that for Experiment 2A, except that $T=6$ rather than 8 periods. The results are summarized in Table 7. It can be seen that although the participants randomly assigned to Group 1 were again less productive overall than the participants randomly assigned to Group 2, the difference was much smaller than in Experiment 2A, with the result that the observed totals were lower than the predicted totals for both pairs of cue words. A two-way ANOVA with group (1 and 2) as the between-subjects variable and condition (observed vs. predicted) as the within-subjects variable confirmed that there was no significant difference between the two groups $[F(1,18)=$ $\left.2.76, M S_{\mathrm{e}}=18.31, p>.1\right]$ and that the observed mean (12.5) was significantly lower than the predicted mean (17.9) $\left[F(1,18)=21.81, M S_{\mathrm{e}}=13.13, p<.0005\right]$. The

Table 6

Mean Totals and Standard Deviations of Items Retrieved in the Either/Or Conditions of Experiment 2A (Observed) and Mean Totals Predicted on the Basis of Exclusivity

\begin{tabular}{cccccc}
\hline & \multicolumn{2}{c}{ Observed } & & \multicolumn{2}{c}{ Predicted } \\
\cline { 2 - 3 } \cline { 5 - 6 } Category & $M$ & $S D$ & & $M$ & $S D$ \\
\hline $\begin{array}{c}\text { Memories associated } \\
\text { with fire } \text { or } \text { picture }\end{array}$ & $11.0^{\mathrm{a}}$ & 5.0 & & $19.0^{\mathrm{b}}$ & 5.9 \\
$\begin{array}{c}\text { Memories associated } \\
\text { with } \text { flower } \text { or } \text { ticket }\end{array}$ & $17.5^{\mathrm{b}}$ & 6.0 & & $15.6^{\mathrm{a}}$ & 4.6 \\
\hline
\end{tabular}

${ }^{\mathrm{a}}$ Group 1, $n=10 . \quad{ }^{\mathrm{b}}$ Group 2, $n=10$. 
Table 7

Mean Totals and Standard Deviations of Items Retrieved in the Either/Or Conditions of Experiment 2B (Observed) and Mean Totals Predicted on the Basis of Exclusivity

\begin{tabular}{cccccc}
\hline & \multicolumn{2}{c}{ Observed } & & \multicolumn{2}{c}{ Predicted } \\
\cline { 2 - 3 } \cline { 5 - 6 } Category & $M$ & $S D$ & & $M$ & $S D$ \\
\hline $\begin{array}{c}\text { Memories associated } \\
\text { with fire } \text { or } \text { picture }\end{array}$ & $11.9^{\mathrm{a}}$ & 4.4 & & $19.5^{\mathrm{b}}$ & 2.5 \\
$\begin{array}{c}\text { Memories associated } \\
\text { with } \text { flower } \text { or } \text { ticket }\end{array}$ & $13.1^{\mathrm{b}}$ & 3.8 & & $16.2^{\mathrm{a}}$ & 4.8 \\
\hline
\end{tabular}

aGroup 1, $n=10$. ${ }^{\text {b Group 2, } n=10 .}$

two-way interaction was not significant $(F<1)$, indicating that fire and picture cue words were as productive as flower and ticket cue words for these participants.

In summary, vocal responses over 3-min retrieval periods resulted in approximately similar numbers of autobiographical memories as for written responses over 4min retrieval periods (cf. Tables 6 and 7). Importantly, the participants again retrieved fewer autobiographical memories from the disjunctive category than predicted on the basis of optimal sequencing of retrieval from the single categories. Moreover, with the removal of the overall group difference, this was now apparent for both pairs of cue words. Finally, there was no evidence of a reduction in the observed-predicted difference with a shift from written to vocal responses, lending further weight to the conclusion from Experiment 1B that output limitations imposed by writing speed are not responsible for the failure to observe nonexclusive search in Experiments 1A and 2A.

\section{GENERAL DISCUSSION}

The results of the present experiments demonstrate that search rates for disjunctive categories do not exceed search rates for the individual component categories for retrieval either from semantic memory (Experiment 1) or from long-term episodic (autobiographical) memory (Experiment 2). This outcome is compatible with the view that memory search is exclusive. It is not readily compatible with the assumption that nonexclusive search is possible, because the ability to search simultaneously for instances of the two categories should lead to an advantage in terms of rate of retrieval, over and above the search rate for individual categories. Thus, the results provide strong support for the view that memory search is exclusive. It remains, of course, logically possible that nonexclusive search can occur, but it occurs in these tasks to such a small extent that the resulting retrieval advantage is not measurable. Moreover, we acknowledge that mimicry theorems concerning serial and parallel cognitive processes (e.g., Townsend, $1971,1976,1990)$ indicate that it is possible to construct a model that allows nonexclusive search but that is consistent with our data. But parsimony dictates that we presume against this possibility unless some positive evidence can be provided for it. In conclusion, we cannot (or, more strictly, we do not) search for two different things at once.
The present results both confirm and considerably extend the findings that Rohrer et al. (1998) obtained using a different experimental method and a relatively brief retention period. The exclusivity of memory retrieval may have large implications for attention. One would expect a bottleneck to arise in dual-task performance of any two tasks that draw on the same, exclusive memory system. For example, Pashler (1998) suggests that the psychological refractory period (PRP; Welford, 1952) may arise in this way. It has been postulated that the PRP arises because response selection must occur sequentially, even though two different responses can be implemented simultaneously. If response selection requires accessing long-term memory in order to determine which response is appropriate, then the exclusivity of memory access might underpin the PRP. To take a very different example, there is evidence that people can understand only one stream of linguistic input at a time, although they may be able to access some aspects of the meaning of a "second" channel. Language understanding requires access to long-term memory in order to make bridging inferences, resolve anaphora, and to support common-sense inferences required to build an appropriate discourse model (Clark, 1977; Johnson-Laird, 1983). If long-term memory access is exclusive, we should expect that only one stream of linguistic input can be processed simultaneously.

The proposal that long-term memory access is exclusive might at first sight seem to be implausible on independent grounds. First, to be able to understand a single stream of language, it is often assumed that large amounts of relevant information must be retrieved simultaneously in order to support appropriate common-sense inferences. Second, as Pashler (1998) notes, exclusivity may appear incompatible with the observation that multiple memory cues can be used to access an item in memory (e.g., think of a female British prime minister). What these examples seem to point to, as noted earlier when we considered evidence for superadditivity among multiple retrieval cues, is that a distinction must be observed between searching for separate items of information and, on the other hand, combining information inferentially. Consider memory as a process of pattern completion over a distributed network of processing units. Superadditivity among multiple retrieval cues may correspond to the fixing of several parts of a pattern and hence may facilitate filling in the rest of the pattern. But the search for multiple targets is analogous to the attempt to complete two patterns at once, which will not be possible if the patterns are distributed over the same processing units.

\section{REFERENCES}

Brown, L. (Ed.). (1993). New shorter Oxford English Dictionary. Oxford: Oxford University Press.

Clark, H. H. (1977). Bridging. In P. N. Johnson-Laird \& P. C. Wason (Eds.), Thinking: Readings in cognitive science (pp. 411-420). Cambridge: Cambridge University Press.

Conway, M. A. (1990). Autobiographical memory: An introduction. Milton Keynes, U.K.: Open University Press. 
Crovitz, H. F., \& Schiffman, H. (1974). Frequency of episodic memories as a function of their age. Bulletin of the Psychonomic Society, 4, 517-518.

Galton, F. (1879). Psychometric experiments. Brain, 2, 149-162.

Herrmann, D. J., \& Murray, D. J. (1979). The role of category size in continuous recall from semantic memory. Journal of General Psychology, 101, 205-218.

Jacoby, L. L., Toth, J. P., Yonelinas, A. P., \& Debner, J. A. (1994). The relationship between conscious and unconscious influences: Independence or redundancy? Journal of Experimental Psychology: General, 122, 216-219.

Johnson-LaIRD, P. N. (1983). Mental models. Cambridge: Cambridge University Press.

Jones, G. V. (1987). Independence and exclusivity among psychological processes: Implications for the structure of recall. Psychological Review, 94, 229-235.

Logan, G. D., \& Delheimer, J. A. (2001). Parallel memory retrieval in dual-task situations: II. Episodic memory. Journal of Experimental Psychology: Learning, Memory, \& Cognition, 27, 668-685.

Logan, G. D., \& Schulkind, M. D. (2000). Parallel memory retrieval in dual-task situations: I. Semantic memory. Journal of Experimental Psychology: Human Perception \& Performance, 26, 1072-1090.

Maylor, E. A., Chater, N., \& Brown, G. D. A. (2001). Scale invariance in the retrieval of retrospective and prospective memories. Psychonomic Bulletin \& Review, 8, 162-167.

PASHler, H. (1998). The psychology of attention. Cambridge, MA: MIT Press.

Rogers, R. D., \& Monsell, S. (1995). Costs of a predictable switch between simple cognitive tasks. Journal of Experimental Psychology: General, 124, 207-231.

Rohrer, D., Pashler, H., \& Etchegaray, J. (1998). When two memories can and cannot be retrieved concurrently. Memory \& Cognition, 26, 731-739.

RuBiN, D. C. (1982). On the retention function for autobiographical memory. Journal of Verbal Learning \& Verbal Behavior, 21, 21-38.

Rubin, D. C., \& Wallace, W. T. (1989). Rhyme and reason: Analyses of dual retrieval cues. Journal of Experimental Psychology: Learning, Memory, \& Cognition, 15, 698-709.

Rubin, D. C., Wetzler, S. E., \& Nebes, R. D. (1986). Autobiographical memory across the adult lifespan. In D. C. Rubin (Ed.), Autobiographical memory (pp. 202-221). Cambridge: Cambridge University Press.
Townsend, J. T. (1971). A note on the identifiability of parallel and serial processes. Perception \& Psychophysics, 10, 161-163.

TownsEND, J. T. (1976). Serial and within-stage independent parallel model equivalence on the minimum completion time. Journal of Mathematical Psychology, 14, 219-239.

Townsend, J. T. (1990). Serial and parallel processing: Sometimes they look like Tweedledum and Tweedledee but they can (and should) be distinguished. Psychological Science, 1, 46-54.

Welford, A. T. (1952). The "psychological refractory period" and the timing of high speech performance: A review and a theory. British Journal of Psychology, 43, 2-19.

WiXted, J. T., \& Rohrer, D. (1994). Analyzing the dynamics of free recall: An integrative review of the empirical literature. Psychonomic Bulletin \& Review, 1, 89-106.

\section{NOTES}

1. In fact, the first two, three, four, and five periods of words beginning with $p$ combined, respectively, with the first six, five, four, and three periods of words beginning with $s$ differed by less than 1 item.

2. For foods/countries, Equation 2 was maximal when, on average, the first 4.05 periods $(S D=1.19)$ of foods were combined with the first 3.95 periods of countries. For musical instruments/occupations, Equation 2 was maximal when, on average, the first 2.20 periods $(S D=0.48)$ of musical instruments were combined with the first 5.80 periods of occupations.

3. An alternative (or additional) explanation is that the participants in Experiment $1 \mathrm{~B}$ just happened to be not very musical. Thus, the total numbers of items retrieved in $2 \mathrm{~min}$ in each category in Experiment $1 \mathrm{~B}$ differed by no more than two items from the total numbers of items retrieved in the first $2 \mathrm{~min}$ of the $4 \mathrm{~min}$ in the single category conditions of Experiment $1 \mathrm{~A}$ (all $p s>.3$ ), with the single exception of musical instruments for which the participants in Experiment 1B recalled four fewer items than those in Experiment 1A $(p<.005)$.

4. The participants were not asked to identify the category to which each memory was associated. We were therefore unable to break down performance in the either/or conditions to record the number of times the participants switched between categories in this experiment.

(Manuscript received January 19, 2001; revision accepted for publication August 7, 2001.) 